\title{
Papers
}

\section{Compliance therapy: a randomised controlled trial in schizophrenia}

Colin O’Donnell, Gary Donohoe, Louise Sharkey, Nicholas Owens, Maria Migone, Raewynn Harries, Anthony Kinsella, Conall Larkin, Eadbhard O’Callaghan

\begin{abstract}
Objective To evaluate the efficacy of "compliance therapy" for improving adherence to prescribed drug treatment among patients with schizophrenia.

Design Randomised controlled trial.

Setting Urban catchment area psychiatric service. Participants 94 consecutive admissions of patients with schizophrenia, 56 agreed to participate.

Intervention Compliance therapy and non-specific counselling, each consisting of 5 sessions lasting 30-60 minutes.

Main outcome measures Compliance with drug treatment at one year; attitudes to treatment, symptomatology, insight, and quality of life at one year; length of "survival" in the community, bed days, and rehospitalisation rates at two years.

Results Compliance therapy did not confer a major advantage over non-specific therapy in improving compliance at one year (43\% (12/28) v 54\% (15/28), difference $-11 \%(95 \%$ confidence interval $-37 \%$ to $15 \%$ ) or in any of the secondary outcome measures-symptomatology, attitudes to treatment, insight, global assessment of functioning, and quality of life.

Conclusion Compliance therapy may not be of benefit to patients with schizophrenia. Attitudes to treatment at baseline predicted adherence one year later and may be a clinically useful tool.
\end{abstract}

\section{Introduction}

People with an illness often have different opinions from their doctor about their treatment. This lack of concordance may lead to adverse health outcomes for people with schizophrenia. ${ }^{1}$ Two thirds of people with schizophrenia readmitted to hospital are partially or completely non-adherent with their medication. ${ }^{2-4}$ Although few randomised controlled trials of interventions to improve adherence have been published, Kemp and colleagues described encouraging results from a brief and pragmatic intervention based on motivational interviewing. ${ }^{5}$ Patients receiving this "compliance therapy" had better drug compliance, attitudes to treatment, and insight at six months. People allocated to the compliance therapy group also "survived" longer in the community than those allocated to non-specific therapy.
We sought to establish the efficacy of compliance therapy among a consecutive series of patients with schizophrenia.

\section{Participants and methods}

\section{Sample}

We asked a consecutive series of people with psychosis, who had been admitted to St John of God Hospital, Dublin, to participate in the trial. After giving written informed consent, each person was interviewed with the structured clinical interview (SCID) to determine their diagnosis according to the Diagnostic and Statistical Manual of Mental Disorders, third edition, revised (DSM-III-R). ${ }^{7}$ We included those who met the criteria for schizophrenia, were aged between 18-65 years, had an IQ greater than 80, were fluent English speakers, and had no evidence of organic disturbance.

\section{Assessment instruments}

We used a structured clinical interview to assess participants' compliance with drug treatment in the month before their admission. ${ }^{2}$ We rated compliance on a four point scale: 1 for $0 \%-24 \%$ compliance (noncompliant or consistently irregular), 2 for $25 \%-49 \%$ compliance (frequently irregular), 3 for $50 \%-74 \%$ compliance (irregular), and 4 for $75 \%-100 \%$ compliance (regular). We obtained further information regarding compliance from key informants, including family members and health professionals, and used this to adjust the compliance ratings. Any participant who scored $\leq 3$ was classified as having suboptimal compliance. We assessed participants' subjective response to neuroleptics and attitude toward medication using the drug attitude inventory (DAI). ${ }^{8}$

We measured symptomatology using the positive and negative symptoms scale (PANSS) and insight using the schedule for assessment of insight (SAI). ${ }^{10}$ To determine overall level of functioning, we used the global assessment of functioning (GAF) and evaluated quality of life with the Heinrichs scale (QLS). ${ }^{11}{ }^{12} \mathrm{We}$ also collected data about each participant's occupancy of psychiatric hospital beds one and two years before the trial started and dose of prescribed neuroleptics. We recorded sociodemographic data, including marital status, living arrangements, and educational levels. We used the national adult reading test (NART) to estimate premorbid IQ. ${ }^{13}$ Routine management, which included
Stanley Research Unit, Department of Adult Psychiatry, Cluain Mhuire Service,

Newtownpark

Avenue, Dublin, Republic of Ireland Colin O'Donnell registrar

Gary Donohoe clinical psychologist

Louise Sharkey registrar Nicholas Owens registrar Maria Migone registrar

Raewynn Harries clinical nurse specialist

Dublin Institute of Technology, Kevin Street, Dublin

Anthony Kinsella statistician

Saint John of God Hospital, Stillorgan, County Dublin

Conall Larkin consultant

Department of Psychiatry,

University College Dublin, St Vincent's University Hospital, Elm Park, Dublin

Eadbhard

O'Callaghan professor

Correspondence to: E O'Callaghan eadbhard@iol.ie

bmj.com 2003;327:834 
appropriate education and discussions about treatment, was continued for all participants.

\section{Intervention}

Compliance therapy is a cognitive behaviour intervention with techniques adapted from motivational interviewing and other cognitive therapies as well as psychoeducation. ${ }^{14}{ }^{15}$ Kemp and David kindly provided their manual to assist in the delivery of compliance therapy. This intervention comprised five sessions, each lasting 30-60 minutes, and covered a review of the patient's illness history and understanding of illness and his or her ambivalence to treatment, maintenance medication, and stigma.

Control patients received non-specific counselling, which also comprised five sessions each lasting 30-60 minutes. When patients raised matters relating to medication they were asked to discuss them with their treating teams.

We randomly allocated consenting patients to compliance therapy or control groups using odd and even digits from a standard table of random numbers.

\section{Outcome measures}

One year after the intervention a researcher who was blind to the type of intervention delivered repeated the assessments of participants' compliance, attitudes to treatment, insight, symptomatology, overall functioning, and quality of life. We also collected data on participants' occupancy of psychiatric hospital beds one and two years after entering the trial.

\section{Statistics}

To detect an improvement from $35 \%$ compliance at baseline to $75 \%$ compliance at completion with $80 \%$ power, we required a sample size of 28 in each arm of the study. We used SPSS (version 10.0) to compare baseline characteristics and the outcome measures between groups. We used a logistic regression model to evaluate the relation between compliance at one year

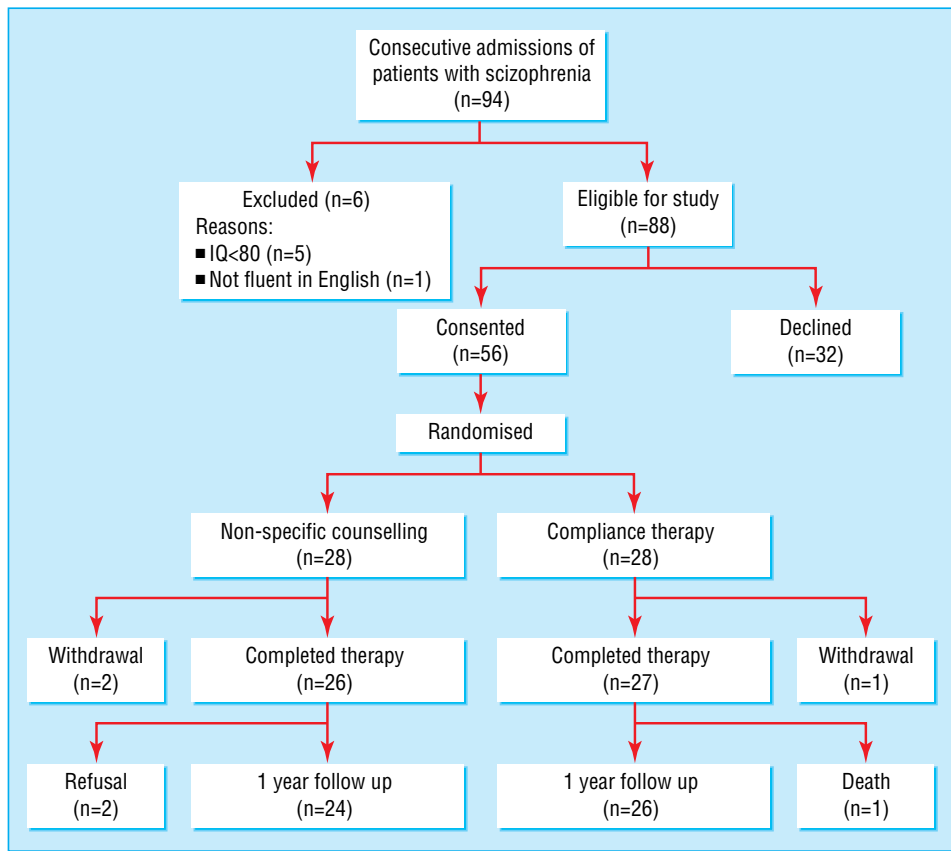

Recruitment of participants and their progress through the trial with baseline measures and type of intervention. We compared the mean number of days to first readmission (survival time) using the Kaplan-Meier time-to-event procedure.

\section{Results}

Ninety four patients met the criteria for schizophrenia, of whom six were ineligible (five had an IQ $<80$, and one person was not fluent in English) and 32 declined to enter the trial. A greater proportion of women than men declined to participate in the trial $(15 / 30(50 \%) v$ $18 / 59(30 \%), \mathrm{P}=0.073)$, and those who refused to participate were significantly older than those who agreed (mean (SD) age 36.95 (11.48) v 31.98 (8.93), difference 4.97 (95\% confidence interval 0.58 to 9.38$), \mathrm{P}=0.028$ ).

The 56 people who consented to enter the study were randomly allocated equally to the two therapies. Six patients were lost to follow up: two dropped out during therapy (both controls); three (two controls, one compliance therapy) refused follow up, and one (compliance therapy) died in the follow up period (see figure).

Baseline compliance could not be measured for the 12 patients who were admitted for their first episode of schizophrenia, five of whom were allocated to compliance therapy and seven to control therapy. Patients randomised to compliance therapy did not differ from control patients in terms of baseline compliance $(8 / 23$ $v 4 / 21$, odds ratio 2.267 (95\% confidence interval 0.474 to 11.41$)$ ), attitudes to medication, insight, symptomatology, level of functioning, or quality of life (table 1).

\section{Outcome measures}

Compliance therapy conferred no advantage over non-specific therapy in terms of compliance at one year $(12 / 28 v 15 / 28$, odds ratio 0.65 (0.197 to 2.123$))$ or the secondary outcome measures-symptomatology (mean (SD) symptoms scale 58.2 (17) v 52.1 (21), difference $6.1(-4.7$ to 16.9$), \mathrm{P}=0.26)$, attitudes to treatment (51.3 (8.2) v 53.4 (6.2), difference $-2.1(-6.3$ to 2.1$), \mathrm{P}=0.32)$, insight (9.9 (4.1) v 10.4 (2.8), difference $-0.5(-2.4$ to 1.5$), \mathrm{P}=0.65)$, level of functioning (52.7 (17.8) $v 56.9$ (25.3), difference -4.2 $(-16.8$ to 8.4$), \mathrm{P}=0.50)$, and quality of life $(71.8(21) v$ 75.2 (25), difference $-3.4(-16.6$ to 9.9$), \mathrm{P}=0.61)$.

Patients who received compliance therapy were not significantly different from control patients in terms of occupancy of psychiatric hospital beds at one year follow up (mean (SD) number of bed days 26 (45) v 33 (57), difference -7 ( -35 to 21$), \mathrm{P}=0.61$ ) and at two years $(43(60)$ v 50 (70), difference -7 ( -42 to 28$)$, $\mathrm{P}=0.69)$. Survival in the community, measured by the number of days to first readmission to psychiatric hospital, was not significantly different for the two groups of patients (mean 440 days (95\% confidence interval 346 to 534) for compliance therapy $v 482$ days (378 to 586) for control).

\section{Predictors of compliance at one year}

A logistic regression model (for the 44 patients with complete baseline data) identified baseline compliance, baseline attitudes to treatment, female sex, and carer involvement as predictors of compliance at one year follow up (table 2). Undergoing compliance therapy was not a predictor of compliance at one year. 
Olfson et al had found that refusal by patients' families to become involved in treatment predicted patients' non-compliance. ${ }^{16}$ We therefore included carer attendance at an education programme in our model as an indicator of willingness to become involved in treatment care, and this was a predictor of compliance at one year.

\section{Discussion}

In this study, compliance therapy for patients with schizophrenia conferred no advantages over nonspecific therapy in terms of patients' compliance with treatment, attitudes to medication, insight, symptomatology, global social functioning, quality of life, or time to readmission to a psychiatric hospital. We were therefore unable to replicate the findings of the previous trial of compliance therapy. ${ }^{56}$

There were, however, important methodological differences between our study and that of Kemp et al, which may help to explain the different findings. ${ }^{5}$ In our study, evaluators at baseline and one year were blind to the intervention offered to the patients. Furthermore, unlike Kemp et al, we focused exclusively on people with schizophrenia. Kemp et al, while reporting an overall positive finding, suggest that those with schizophrenia had a less favourable outcome "in terms of social functioning, symptom level, insight and treatment attitudes." ${ }^{\prime 6}$ Our findings indicate that people with schizophrenia may not benefit from compliance therapy.

\section{Limitations of study}

The patients in our study were not representative of the entire spectrum of people with schizophrenia because they were consecutively admitted patients from a geographically defined area. In this group, we found a non-compliance rate of $72 \%$, which is similar to that previously found in this area and markedly more than that of a typical outpatient group. ${ }^{47}$ The high proportion of patients who refused to participate in our study (36\%) was similar to that found by Kemp et al and might be expected among a population of whom $72 \%$ were non-compliant with treatment. ${ }^{6}$

Like Kemp et al, we relied on the reports of patients and their relatives and healthcare professionals for our measure of compliance. This is not ideal and, like pill counts and serum drug levels, probably overestimates compliance. $^{18}$ Electronic measurement is methodologically superior but is expensive, is not foolproof, and can be difficult to use. $^{19}$ We have no reason to believe that using a self report method led to a systematic bias.

We assessed major outcome measures at one year because we believed that if sustained benefit ensued from compliance therapy it should still be evident at that time. It is possible that the compliance therapy group did benefit transiently from the therapy but that the benefit waned within one year and was consequently not detected by us. Our follow up period was longer than in the initial study by Kemp et al. ${ }^{5}$ In a later paper, however, they showed persistent benefit from compliance therapy at 18 months. $^{6}$ Although our major outcome measures were evaluated at one year, we did follow two outcome variables (bed days in a psychiatric hospital and days to readmission) for two years and found no benefit in the compliance therapy group.
Table 1 Baseline sociodemographic and clinical characteristics of patients with schizophrenia who received compliance therapy or non-specific counselling. Values are numbers of patients unless stated otherwise

\begin{tabular}{lcc} 
Baseline measures & $\begin{array}{c}\text { Compliance therapy } \\
(\mathbf{n = 2 8})\end{array}$ & $\begin{array}{c}\text { Non-specific counselling } \\
(\mathbf{n}=\mathbf{2 8})\end{array}$ \\
\hline Mean (SD) age (years) & $32(9)$ & $32(9)$ \\
\hline Men & 19 & 22 \\
\hline Mean (SD) No of years of illness & $6(7)$ & $4(5)$ \\
\hline $\begin{array}{l}\text { Mean (SD) No of bed days in psychiatric hospital } \\
\text { in previous 2 years }\end{array}$ & $77(64)$ & $83(52)$ \\
\hline First episode of schizophrenia & 5 & 7 \\
\hline Detained under Mental Treatment Act & 4 & $114(6)$ \\
\hline $\begin{array}{l}\text { Mean (SD) national adult reading test (NART) score } \\
\text { Mean (SD) neuroleptic dose (in chlorpromazine } \\
\text { equivalents) }\end{array}$ & $111(7)$ & $883(715)$ \\
\hline
\end{tabular}

\section{caress invol}

\begin{tabular}{lll}
\hline Carers involved & 11 & 11 \\
\hline Domestic sityation:
\end{tabular}

\begin{tabular}{lcc}
\hline Living alone & 2 & 3 \\
\hline Living with family or friends & 22 & 22 \\
\hline In residential services & 4 & 2
\end{tabular}

\begin{tabular}{lll}
\hline In residential services & 4 & 2 \\
\hline Homeless & 0 & 1 \\
\hline
\end{tabular}

\begin{tabular}{lll} 
Marital situation: & 0 & 1 \\
\hline
\end{tabular}

\begin{tabular}{lcc}
\hline Marital situation: & 26 & 25 \\
\hline Single & 2 & 3 \\
\hline Married or cohabiting & &
\end{tabular}

\begin{tabular}{lcc} 
Substance misuse: & 15 & 14 \\
\hline None & 4 & 5 \\
\hline Alcohol only & 8 & 7
\end{tabular}

Multiple substances

Education:

\begin{tabular}{lcc}
\hline No state exams (education to 12-14 years old) & 6 & 6 \\
\hline State exams (education to 15-18 years) & 15 & 13 \\
\hline Third level education & 7 & 9 \\
\hline Clinical measures: & $8 / 23(35 \%)$ & $4 / 21(19 \%)$ \\
\hline Full compliance at baseline ${ }^{*}$ & $71(22)$ & $66(17)$ \\
\hline Mean (SD) symptoms score (PANSS) & $36(14)$ & $31(12)$ \\
\hline Mean (SD) functioning score (GAF) & $50(8)$ & $50(7)$ \\
\hline Mean (SD) attitude to treatment (DAl) & $9(4)$ & $9(4)$ \\
\hline Mean (SD) insight score (SAl) & $67(22)$ & $66(22)$ \\
\hline Mean (SD) quality of life score
\end{tabular}

${ }^{\star}$ Excluding patients for whom this was their first episode of schizophrenia.

PANSS=positive and negative symptoms scale, GAF=global assessment of functioning, DAl=drug attitude inventory, SAl=schedule for assessment of insight.

Table 2 Baseline predictors of optimal compliance with drug treatment at one year among patients with schizophrenia with full baseline date $(n=44)$. Results of binary logistic regression analysis (intention to treat analysis)

\begin{tabular}{lccc} 
& B coefficient (SE) & P value & Odds ratio (95\% Cl) \\
\hline Attitude to treatment (DAI) & $0.31(0.11)$ & 0.006 & $1.36(1.09$ to 1.70$)$ \\
\hline Symptoms (PANSS) & $-0.06(0.03)$ & 0.059 & $0.95(0.89$ to 1.00$)$ \\
\hline Baseline suboptimal compliance & $2.50(1.42)$ & 0.081 & $11.89(0.73$ to 193$)$ \\
\hline Baseline compliance & $3.39(1.69)$ & 0.045 & $29.59(1.08$ to 812$)$ \\
\hline Sex & $-4.60(1.75)$ & 0.008 & $0.01(0.00$ to 0.30$)$ \\
\hline Compliance therapy & $-1.74(1.36)$ & 0.201 & $0.17(0.01$ to 2.51$)$ \\
\hline Insight score (SAI) & $-0.18(0.21)$ & 0.392 & $0.84(0.56$ to 1.25$)$ \\
\hline Carer involvement & $-6.72(2.27)$ & 0.003 & $0.001(0.00$ to 0.10$)$ \\
\hline NART score & $-0.07(0.08)$ & 0.344 & $0.93(0.80$ to 1.08$)$ \\
\hline Constant & $4.73(9.67)$ & 0.631 & \\
\hline
\end{tabular}

DAl=drug attitude inventory, PANSS=positive and negative symptoms scale, SAl=schedule for assessment of insight, NART=national adult reading test.

Furthermore, because our sample size was modest we cannot exclude the possibility that compliance therapy had the desired effect. Although we had limited power to detect subtle changes in second line outcome measures, it was sufficient to confirm previously identified predictors of adherence.

\section{Predicting adherence to drug treatment}

The factors that influence a person's adherence to a drug regimen may vary over time. Few prospective 


\section{What is already known on this topic}

Non-concordance with drug treatment is a major reason for relapse in schizophrenia

Substantial advantages have been attributed to compliance therapy on measures of patients' insight, attitudes to treatment, compliance with treatment, social functioning, and survival in the community before readmission to hospital

\section{What this study adds}

This randomised controlled trial of compliance therapy for schizophrenia failed to replicate the previous findings and found no advantage over non-specific therapy in terms of patients' adherence

Attitudes to medication and carer involvement were useful predictors of compliance a year later

studies have examined this issue in schizophrenia. In our study, previous compliance, being female, and carer involvement were associated with adherence- $-\mathrm{a}$ finding that confirms previous reports. ${ }^{16} 2021$

This study also prospectively confirmed that measuring a patient's attitudes to drug treatment with a self report instrument predicts adherence one year later. Given the serious personal, familial, and societal consequences of non-compliance, self report instruments have a potential role in clinical practice. However, our findings suggest that, although noncompliance may be increasingly identifiable and predictable, it remains difficult to solve.

We thank all the clinicians who supported the trial and especially the participants. We are grateful to Stephen Browne, consultant psychiatrist, Waterford Regional Hospital, for his timely and stimulating advice. We thank Anne Tobin, medical director, Eli Lilly (Ireland), for her advice and encouragement at the study design stage.

Contributors: EO'C, GD, AK, and CL designed the study. CO'D, LS, NO, and MM conducted the baseline and outcome assessments. GD and RH delivered the therapy. GD, EO'C, and CO'D coordinated the study. CO'D, GD, AK, EO'C, and CL participated in the analyses. CO'D, EO'C, AK, and GD wrote the initial draft, and all authors participated in writing the final manuscript. All authors approved the final document. EO'C is guarantor for the study.
Funding: This project was supported by the Stanley Medical Research Institute. GD was supported by an unrestricted educational grant from Eli Lilly (Ireland).

Competing interests: None declared.

Ethical approval: The study was approved by the Provincial Ethics Committee of the Hospitaller Order of Saint John of God.

1 Lewis CF, Tandon R, Shipley JE, DeQuardo JR, Jibson M, Taylor SF, et al Biological predictors of suicidality in schizophrenia. Acta Psychiatr Scand 1996:94:416-20.

2 Adams SG Jr, Howe JT. Predicting medication compliance in a psychotic population. J Nerv Ment Dis 1993;181:558-60.

3 Fenton WS, Blyler CR, Heinssen RK. Determinants of medication compliance in schizophrenia: empirical and clinical findings. Schizophr Bull 1997;23:637-51.

4 Kamali M, Kelly L, Gervin M, Browne S, Larkin C, O'Callaghan E. Psychopharmacology: insight and comorbid substance misuse and medication compliance among patients with schizophrenia. Psychiatr Serz 2001;52:161-3, 166.

5 Kemp R, Hayward P, Applewhaite G, Everitt B, David A. Compliance therapy in psychotic patients: randomised controlled trial. BMJ 1996:312:345-9.

6 Kemp R, Kirov G, Everitt B, Hayward P, David A. Randomised controlled trial of compliance therapy. 18-month follow-up. Br J Psychiatry

7 American Psychiatric Association. Structured clinical interview for the DSM III-R. Washington DC: American Psychiatric Press, 1992.

8 Hogan TP, Awad AG, Eastwood R. A self-report scale predictive of drug compliance in schizophrenics: reliability and discriminative validity. Psychol Med 1983;13:177-83.

9 Kay SR, Fiszbein A, Opler LA. The positive and negative syndrome scale (PANSS) for schizophrenia. Schizophr Bull 1987;13:261-76.

10 David AS. Insight and psychosis. Br J Psychiatry 1990;156:798-808.

11 Endicott J, Spitzer RL, Fleiss JL, Cohen J. The global assessment scale. A procedure for measuring overall severity of psychiatric disturbance. Arch Gen Psychiatry 1976;33:766-71.

12 Heinrichs DW, Hanlon TE, Carpenter WT Jr. The quality of life scale: an instrument for rating the schizophrenic deficit syndrome. Schizophr Bull $1984 ; 10: 338-98$.

13 Nelson HE. National adult reading test (NART): test manual. Windsor: NFER, 1984.

4 Rollnick S, Kinnersley P, Stott N. Methods of helping patients with behaviour change. BMJ 1993;307:188-90.

15 John C, Turkington D, Kingdon D. Cognitive-behavioural therapy for schizophrenia. Br J Psychiatry 1994;165:695.

16 Olfson M, Mechanic D, Hansell S, Boyer CA, Walkup J, Weiden PJ Predicting medication non-compliance after hospital discharge among patients with schizophrenia. Psychiatr Serv 2000;51:216-22.

17 Garavan J, Browne S, Gervin M, Lane A, Larkin C, O'Callaghan E. Compliance with neuroleptic medication in outpatients with schizophrenia; relationship to subjective response to neuroleptics; attitudes to medication and insight. Compr Psychiatry 1998;39:215-9.

18 Haynes RB, Taylor DW, Sackett DL, Gibson ES, Bernholz CD, Mukherjee J. Can simple clinical measurements detect patient non-compliance? Hypertension 1980;2:757-64.

19 Diaz E, Levine HB, Sullivan MC, Sernyak MJ, Hawkins KA, Cramer JA, et al. Use of the medication event monitoring system to estimate medication compliance in patients with schizophrenia. J Psychiatry Neurosci 2001;26:325-9.

20 Smith TE, Hull JW, Anthony DT, Goodman M, Hedayat-Harris A, Felger $\mathrm{T}$, et al. Post-hospitalisation treatment adherence of schizophrenic patients: gender differences in skill acquisition. Psychiatry Res 1997;69:123-9.

21 Sellwood W, Tarrier N. Demographic factors associated with extreme non-compliance in schizophrenia. Soc Psychiatry Psychiatr Epidemiol 1994;29:172-7.

(Accepted 8 September 2003) 